\title{
Jovens transexuais: Acesso a serviços médicos, medicina e diagnóstico
}

\author{
Brena 0'Dwyer* \\ Maria Luiza Heilborn**
}

\section{Resumo}

0 presente estudo enquadra-se em um conjunto de pesquisas que, a partir dos anos 2000, busca analisar a transexualidade mediante a crítica à patologização de identidades de gênero que operam fora do modelo que relaciona diretamente sexo anatômico ao gênero. 0 objetivo principal do artigo é descrever a relação de quatro jovens trans com a medicina, diagnóstico e serviços de saúde. Foram realizadas entrevistas semiestruturadas com quatro jovens com idades entre 18 e 22 anos. Apresentamos uma breve historicização da definição da transexualidade enquanto patologia; descrevemos as principais ideias médicas envolvidas na criação do "Processo Transexualizador" do Sistema Único de Saúde no Brasil. Por último, pretendemos apontar como determinadas exigências morais originam-se na noção de que a expressão de gênero está ancorada, em última instância, no sexo biológico.

\section{Palavras-chave}

Gênero. Transexualidade. Serviços de saúde.

\begin{abstract}
The present study seeks to analyze transsexuality by the means of critic of the patologization of gender identities that operate outside the model that puts in relation gender and the anatomic sex. The main objective is to describe the relation of four young transsexual women with the medical science, diagnosis and health services. Interviews were held with four young transsexual women between the ages of 18 to 22 years old. We present a brief historicization of the process of definition of transsexuality as a pathology, describe the main medical ideas held in the creation of the "Processo Transexualizador" in the Sistema Único de Saúde in Brazil.
\end{abstract}

\footnotetext{
* Brena O’Dwyer é mestre em Saúde Coletiva pelo Instituto de Medicina Social (IMS) da Universidade do Estado do Rio de Janeiro (UERJ), e doutoranda em Antropologia Social no Programa de Pós-Graduação em Antropologia Social (PPGAS) do Museu Nacional (MN) / Universidade Federal do Rio de Janeiro (UFRJ). E-mail: brenaspina@gmail.com.

** Maria Luiza Heilborn é doutora em Antropologia Social pelo Programa de Pós-Graduação em Antropologia Social (PPGAS) do Museu Nacional (MN) / Universidade Federal do Rio de Janeiro (UFRJ), e professora associada no Instituto de Medicina Social (IMS) da Universidade do Estado do Rio de Janeiro (UERJ). E-mail: mlheilborn@terra.com.br.
} 
Finally, we point out how moral demands are intricated in the idea that gender expression is rooted in the biological sex.

\section{Keywords}

Gender. Transsexuality. Health services.

\section{Introdução}

O presente estudo enquadra-se em um conjunto de pesquisas que, a partir dos anos 2000, busca analisar a transexualidade mediante a crítica à patologização de identidades de gênero que operam fora do modelo que relaciona diretamente sexo anatômico ao gênero (ALMEIDA, 2012; ARÁN; MURTA, 2009; BENTO, 2006; BORBA, 2014; O’DWYER, 2016). Historicamente existe uma tendência da medicina moderna de classificar como patologia modelos de gênero e sexualidade que não se enquadram no formato heteronormativo e nas classificações tradicionais de gênero ${ }^{1}$.

$\mathrm{Na}$ mesma linha, a transexualidade vem sendo tratada pela medicina como um transtorno mental. Em contraposição, as ciências humanas principalmente os estudos de gênero - questionam tal classificação.

Bento (2006) e Borba (2014) criticam a categoria psiquiátrica "transexual verdadeiro", isto é, aquele que se encaixa nas descrições médicas do "transexualismo". Segundo os autores, tal noção acaba por universalizar a experiência transexual, como se a transexualidade pudesse ser definida a partir de "sintomas" claros e específicos; eles sustentam que existem inúmeras formas de se vivenciar a transexualidade. Esse tipo de perspectiva concebe a transexualidade como um campo frutífero para as investigações sobre gênero e sexualidade ${ }^{2}$.

\footnotetext{
${ }^{1}$ A homossexualidade foi considerada um transtorno psiquiátrico - "homossexualismo" - até o ano de 1972, quando perde esse status graças à pressão do movimento gay (CONRAD, 2007). Da mesma forma, a intersexualidade - "hermafroditismo" - é considerada uma doença, e a intervenção médica nesses corpos é corrente, apesar dos protestos do movimento intersexual (MACHADO, 2005).

${ }^{2}$ Existe uma tensão entre as definições médicas patologizantes da transexualidade e as formas que recusam o enquadramento do corpo nas vias institucionalizadas da medicalização (ZORZANELLIE et al., 2014). Este trabalho enquadra-se na segunda linha, reafirmando a autonomia dos sujeitos para reivindicarem a própria identidade e para realizar intervenções corporais sem necessidade de laudo psiquiátrico.
} 
O objetivo principal do artigo ${ }^{3}$ é descrever a relação de quatro jovens trans com a medicina, diagnóstico e serviços de saúde. Para tal, apresentamos uma breve historicização da definição da transexualidade enquanto patologia; descrevemos as principais ideias médicas envolvidas na criação do "Processo Transexualizador" do Sistema Único de Saúde no Brasil. Os objetivos secundários são: descrever como foi o acesso das entrevistadas a serviços de saúde, se buscaram serviços públicos ou privados e por quê; como foi a relação com médicos e outros profissionais de saúde; descrever como fazem uso de hormônios com e sem indicação médica, apontar a ambiguidade do diagnóstico psiquiátrico de "transexual verdadeiro" na opinião das jovens e discutir como a patalogização da transexualidade é feita a partir de normas morais e não médicas. Por último, pretendemos apontar como essas exigências morais originam-se na noção de que a expressão de gênero está ancorada, em última instância, no sexo biológico.

O tema do gênero é central, já que o artigo pretende explorar como exigências morais de gênero são traduzidas em diagnósticos e determinados tratamentos nos serviços de saúde. Aqui, gênero será entendido como

“O conceito corrente utilizado para designar os modos de classificar as pessoas como pertencentes a mundos sociais, a princípio, organizados pelas diferenças de sexo. A expressão identidade de gênero alude à forma como um indivíduo se percebe e é percebido pelos outros como masculino ou feminino, de acordo com os significados que esses termos têm na cultura a que pertence. Os seres humanos se caracterizam por possuírem um corpo sexuado, que os distingue em função de sua genitália. Possuir um sexo biológico, no entanto, não implica automaticamente uma identificação com as convenções sociais de um determinado contexto, no que concerne a ser homem ou mulher. O lugar simbólico a ser ocupado nas relações com os outros, os tipos de roupa que deve vestir, os comportamentos prescritos e os interditados, além dos sentimentos que são

\footnotetext{
${ }^{3}$ Este artigo é em grande medida fruto da dissertação de mestrado "A construção do gênero nas relações amorosas: um estudo com mulheres transexuais jovens e o processo de feminização" (O'DWYER, 2016). As entrevistas foram realizadas no âmbito desta pesquisa. O estudo sobre as definições médicas do "transexualismo" e sobre o Processo Transexualizador foram analisados no primeiro capítulo da dissertação, entretanto, realizamos diversos aprimoramentos e trouxemos novas discussões e conclusões, especialmente sobre a publicização das identidades trans.
} 
associados a um determinado sexo/gênero, definem a identidade de gênero". (ZAMBRANO; HEILBORN, 2012, p.412).

A literatura brasileira sobre transexualidade tem se detido principalmente no processo de transformação corporal e tem focalizado pessoas adultas. Entretanto, existem singularidades de geração no processo de feminização e na sociabilidade trans. O ponto de vista das jovens entrevistadas é marcado por um acesso à informação mais qualificado que em outras faixas etárias graças às novas tecnologias, principalmente ao uso de mecanismos de busca na Internet em cuja cultura elas foram amplamente socializadas. Também há o impacto que as inovações tecnomédicas promovem no processo de modificação corporal iniciado pelas moças com o intuito de feminizar os corpos.

A opção etária implica um enfoque diferenciado, porque existem mudanças recentes a partir do aumento de visibilidade da causa transexual. Além disso, por uma questão geracional, o início dos processos de feminização das jovens é posterior à criação do Processo Transexualizador no Sistema Único de Saúde (SUS) em 2008.

Para além das singularidades geracionais, a importância da juventude mostra-se por ser um período de transição para a vida adulta e de construção de identidade pessoal. Nas sociedades contemporâneas, a juventude é caracterizada como um momento inconstante e descontínuo, no qual o papel familiar é ambivalente; como lócus referencial, mas que está sendo substituído por outros grupos de socialização (PAIS, 1993, p. 8; HEILBORN, 2006).

A interpretação do senso comum da juventude como um momento de indecisãoéaquiquestionada socioantropologicamentea partir da valorização do discurso juvenil. Ainda que os jovens sejam vistos pelos adultos como irresponsáveis e até certa medida incapazes, a sociologia não precisa fazer o mesmo. Os discursos das jovens sobre as mudanças corporais que desejam fazer, inclusive sobre as transformações consideradas irreversíveis, sobre o abandono da figura masculina e sobre suas identidades é constantemente questionado na escola, na universidade e no ambiente familiar (O'DWYER, 2016). Ainda assim, elas se mostram resolutas com seus planos, indicando uma assertividade que permanece ao longo do tempo, que não condiz com a noção de que a juventude é marcada pela indecisão.

Foram realizadas entrevistas semiestruturadas com quatro jovens 
com idades entre 18 e 22 anos: Ana, Gabriela, Maria Eduarda e Vitória ${ }^{4}$. As jovens vivem com seus familiares - respectivamente: Ana mora com mãe, pai e irmão mais novo; Gabi e Duda vivem com as mães e Vitória mora com a mãe e irmãos, frequentando a casa do pai aos fins de semana - e estão cursando o ensino superior. Tais características as diferenciam da população trans mais geral, que tem baixos níveis de escolaridade e muitas vezes são expulsas de casa pelas famílias (ARÁN; MURTA, 2009).

Maria Eduarda e Vitória são residentes do Rio de Janeiro, e as entrevistas foram conduzidas face a face, com duração aproximada de três horas. Gabriela e Ana residem nas regiões Nordeste e Sul do Brasil, respectivamente, e foram entrevistadas através da ferramenta inbox no Facebook $^{5}$. Cada uma foi entrevistada duas vezes, e cada entrevista durou cerca de três horas ${ }^{6}$.

A Internet foi fundamental para a pesquisa como um meio de acesso às moças. Ela é também um significativo marcador geracional, um mecanismo de interação e um elemento facilitador de sociabilidade (ILLOUZ, 2011).

Por fim, seguimos a sugestão de Benedetti (2005), que fala de suas entrevistadas travestis no feminino para valorizar o trabalho de construção de gênero e respeitar as reivindicações das organizações de travestis e transexuais. Assim como o autor, consideramos não poder ignorar o lado político do saber científico e, portanto, ao chamar as entrevistadas da pesquisa pelo gênero feminino, alinhamo-nos com os preceitos dessa luta. Da mesma forma, sobre a relação entre política e produção de conhecimento, Zilli (2017), no artigo "Teorias que libertam", analisa entrevistas de intelectuais e ativistas brasileiros ligados ao campo dos direitos sexuais para compreender a gramática emotiva que informa o engajamento político e intelectual nas temáticas de sexualidade e gênero. $O$ autor identifica que as pessoas estariam propensas a se envolver a partir de

\footnotetext{
${ }^{4}$ Todos os nomes são fictícios, para manter o anonimato das entrevistadas.

${ }^{5} \mathrm{O}$ Facebook é uma rede social virtual na qual as pessoas criam perfis; adicionam amigos e conhecidos; pode-se seguir páginas de pessoas, empresas e organizações, há publicações de fotos, opiniões, narrativas de acontecimentos e links para outros sites. Todas essas atividades são públicas e podem ser vistas por outros usuários. O inbox é uma ferramenta de conversa privada entre uma ou mais pessoas e funciona nos moldes de outros chats virtuais, como o icq e Msn. É um mecanismo de mensagem similar ao SMS e ao $e$-mail.

${ }^{6}$ Foram poucas as entrevistas, pois se trata de uma experiência bastante circunscrita (tal qual a experiência dos "casais grávidos" analisados por Salem (2007) na década de 1980. Contudo, as entrevistas foram longas, e as trajetórias das jovens apresentam-se extremamente singulares.
} 
um "choque moral" que se transforma em inquietude e leva à ação social. Segundo Zilli, a inquietude pode se dar em relação a como certas teorias lidam com problemas sociais e, assim, levar a uma mobilização na direção à intelectualidade. Esta visa propor novas teorias para pensar determinado problema social no âmbito dos direitos sexuais, a partir de uma gramática emocional da inquietude que leva à ação social, como é o caso do presente artigo.

\section{Transexualidade: um breve panorama}

Joanne Meyerowitz (2004), historiadora americana, descreve a história da transexualidade nos Estados Unidos a partir do caso de Christine Jorgensen. Do ponto de vista de Meyerowitz, a transexualidade construiuse em larga medida através da publicidade em torno desse caso na mídia americana. Em 1952, Christine Jorgensen aparece em uma matéria no New York Daily News narrando sua "mudança de sexo" e, a seguir, ela se torna uma celebridade nacional.

Nascida em 1926 na cidade de Nova York, Jorgensen entra para o exército americano e luta na Segunda Guerra Mundial. No fim da guerra, retorna aos EUA e começa a tomar hormônios para adquirir características corporais socialmente tidas como femininas. Descobre um centro médico na Dinamarca, onde cirurgias de modificação genital eram feitas. Em 1951, é operada e, em seguida, retorna aos EUA, onde sua história é contada em diversos jornais e revistas. A publicidade gerada despertou o interesse de indivíduos que se identificaram com a trajetória de Jorgensen e passaram a buscar médicos em busca de tratamentos semelhantes.

Dado que os sujeitos buscavam ajuda e intervenções em consultórios médicos e psicológicos, as duas disciplinas precisaram debater o fundamento dos "papéis sexuais"7. Entretanto, naquele momento, não havia consenso entre os médicos e cientistas sobre a determinação dos "papéis sexuais"; poderiam ser psicológicos, hormonais, sociais ou outros. Apesar do debate, nos anos 1950, as explicações psicológicas prevaleciam, e por isso tratamentos hormonais ou cirúrgicos não eram recomendados.

\footnotetext{
${ }^{7} \mathrm{O}$ conceito de "papéis sexuais" à época era a definição corrente e pode ser comparado à ideia contemporânea de comportamentos generificados.
} 
Mesmo com uma crescente demanda, Jorgensen permanecia como exceção.

No início dos anos 1960 o cenário começa a mudar. Surge a noção de "sexo psicológico" produzida por Robert Stoller (1982). Segundo tal concepção, este consolida-se até os quatro anos de idade e depois não pode mais ser modificado. O "sexo psicológico" era entendido como permanente, assim a opção de tratamento que restava para os indivíduos adultos - que descreviam que sua identidade, comportamento e emoções não estavam de acordo com o corpo - era a intervenção cirúrgica e hormonal (MEYEROWITZ, 2014).

Com essa nova definição e a crescente demanda de pessoas por alterações corporais, centros médicos começam a surgir nos EUA. As pessoas que procuravam os centros eram diversificadas, mas tinham em comum o desejo - descrito pelos médicos como "obsessão" - de modificar o corpo. Tais pessoas tinham convicção seja de que eram homens seja de que eram mulheres, mas seus corpos os traíam, tinham "nascido no corpo errado".

\section{Debate sobre "transexualismo" na saúde mental}

O debate médico sobre a definição, etiologia e tratamento adequados para o "transexualismo"8 que ocorreu nas décadas de 1950 a 1980, analisado pela historiadora americana Meyerowitz (2014), gira em torno de três figuras centrais: o psiquiatra Robert Stoller (1982), o psicólogo John Money (apud MEYEROWITZ, 2014) e o endocrinologista Harry Benjamin (1966).

Os estudos críticos sobre o fazer científico põem em evidência que a discussão médica sobre normalidade e patologia - assim como qualquer pesquisa - não diz respeito somente a fatos, mas se vale fortemente do campo dos valores (CANGUILHEM, 1990). Da mesma forma, como apresentaremos ao longo do artigo, as definições médicas sobre o "transexualismo" não são isentas de noções morais sobre gênero e sexualidade.

$\mathrm{O}$ "transexualismo" enquanto vivência e como doença deriva de uma sociedade que possui uma estrutura binária de gêneros. Depende também do entendimento de que cada um desses esteja necessariamente conectado

\footnotetext{
${ }^{8} \mathrm{O}$ sufixo "ismo" na psiquiatria indica uma patologia, enquanto o sufixo "ade", reivindicado pelo movimento social - em transexualidade -, indica um estado e não tem conotação negativa. Assim, utilizamos o termo transexualismo entre aspas para indicar a patologização de tal condição.
} 
a um corpo sexuado. Existem, no âmbito das sociedades ocidentais, normas de gênero que atribuem condutas e expectativas sociais aos indivíduos conforme seus corpos; o "transexualismo" é a patologia da qual padecem os que fogem desta regra.

Robert Stoller foi um psiquiatra americano e pesquisador na Clínica de Identidade de Gênero da Universidade da Califórnia em Los Angeles. Suas teorias sobre "identidade de gênero" foram centrais para a definição de "transexualismo". Para Stoller (1982), era necessário distinguir os "verdadeiros transexuais" de sujeitos com outras patologias ligadas a "identidade de gênero" e orientação sexual, para garantir o tratamento adequado.

$\mathrm{O}$ "verdadeiro transexual", para ele, é "uma pessoa anatomicamente normal que se sente como membro do sexo oposto e, consequentemente, deseja trocar seu sexo, embora suficientemente consciente de seu verdadeiro sexo biológico". Para Stoller, a causa do "transexualismo" seria o não desenvolvimento do complexo de Édipo na infância (1982, p. 28). Stoller entendia que, se o "transexualismo" fosse diagnosticado na infância, seria possível revertê-lo através de terapia psicológica. Seria o papel do terapeuta representar uma figura masculina de modo a induzir o complexo de Édipo na criança e reverter qualquer tendência à feminização'

A teoria stolleriana sobre "identidade de gênero" é paralela à concepção feminista de gênero da época. Ambos definem o gênero com os significados culturais, históricos e psicológicos associados ao sexo, sendo este anatômico, morfológico e fisiológico.

Pode parecer paradoxal que a definição de "identidade de gênero" como socialmente construída abra precedentes para tratamentos psicológicos, intervenção cirúrgica e hormonal. Entretanto, para o autor, a "identidade de gênero" fixa-se no psicológico dos sujeitos até os quatro anos. Depois dessa idade a ideia que a pessoa faz de si não pode mais ser modificada, mas seu corpo pode ser adequado a esse pensamento (STOLLER, 1982). Assim, a intervenção cirúrgica aparece não como forma de normalizar a pessoa que continuará padecendo do "transexualismo", mas apenas para

\footnotetext{
${ }^{9}$ Em seu estudo de 1975 chamado "A experiência transexual", Stoller baseia sua teoria em estudos de caso com "meninos" que se entendiam enquanto "meninas" e abrange sua teoria a partir do entendimento de que com "meninas masculinizadas" o mesmo princípio se aplica, mas a partir do Complexo de Elektra.
} 
aplacar o sofrimento individual. De qualquer forma, para o psiquiatra, o ideal é diagnosticar a tendência na infância e corrigi-la através de terapia.

John Money foi um psicólogo e sexologista envolvido no debate sobre "hermafroditismo", fundou a Clínica de Identidade de Gênero do Hospital John Hopkins nos Estados Unidos. Foi pioneiro nos estudos psicológicos sobre a fluidez sexual e afirmava que o gênero era socialmente construído e que esse processo teria impactos individuais, assim como Stoller. Money tomou notoriedade por ter se envolvido, nos anos 1960, em um caso considerado emblemático. O caso David Reimer. David nasceu com pênis, foi identificado como um menino e começou a ser socializado segundo essa designação. Aos dois anos David sofre uma mutilação genital e sua família inicia tratamento com Money. A criança passa por uma cirurgia genital e é criada como menina a partir daquele momento. O caso passa a ser prova de que a identidade de gênero é socialmente construída na infância. Ao chegar à adolescência, Reimer nega a identidade feminina, na vida adulta casa com uma mulher e adota dois filhos, aos 38 anos Reimer comete suicídio ${ }^{10}$ (O'DWYER, 2016).

Harry Benjamin foi um endocrinologista alemão radicado nos EUA. Para o médico, o sexo era um conceito complexo composto por diversas esferas: cromossomática, genética, gonodal, endocrinológica, anatômica, legal, psicológica e social. Para Benjamin (1966), a sintonia entre essas esferas caracterizava o sujeito normal. Entretanto, existe uma hierarquia entre essas dimensões, na qual o sexo cromossomático e genético tem prioridade sobre os outros.

Assim como Stoller e Money, Benjamin compreende que o senso de identidade dos sujeitos não pode ser alterado e por isso recomendava tratamento hormonal para seus pacientes. $\mathrm{O}$ "sexo verdadeiro" não era modificado, mas a aparência da pessoa poderia ser. Na perspectiva do endocrinologista, os sujeitos transexuais viveriam uma espécie de farsa.

Apesar dos diferentes entendimentos que esses três autores construíram sobre o "transexualismo", suas teorias convergiram no que concerne ao status do sexo biológico como imutável e primordial em relação ao gênero; na necessidade de diferenciar o "transexualismo" de outras doenças, como

\footnotetext{
${ }^{10}$ Corrêa (2004) entende que o caso Reimer não pode ser considerado uma prova da origem biológica dos comportamentos generificados, porque uma criança de dois anos já poderia ter se identificado com uma identidade masculina.
} 
o "homossexualismo" e o "travestismo", e na importância do tratamento hormonal e cirúrgico para suavizar o sofrimento dos sujeitos ainda que não houvesse possibilidade real de "cura". Por último, esses estudiosos definiram a importância do diagnóstico psicológico e psiquiátrico como condição de acesso para os tratamentos ${ }^{11}$.

Para Benjamin, por exemplo, a base orgânica do "transexualismo" ainda não havia sido descoberta, mas isto era apenas uma questão de tempo. $\mathrm{O}$ médico não era simpatizante das teorias psicanalíticas e procurava respostas na endocrinologia (HENRI-CASTELL, 2001).

Essas teorias formam a base do conhecimento sobre a transexualidade e tiveram influência na formação do "Processo Transexualizador" do Sistema Único de Saúde, como será discutido. Entretanto, o alcance dessas teorias está para além dos limites da discussão médica, elas são amplamente criticadas no movimento LGBTQI, que propõe a despatologização da transexualidade.

\section{Brasil: o Sistema Único de Saúde e o Processo Transexualizador ${ }^{12}$}

\section{O Sistema Único de Saúde (SUS) foi instituído pela Constituição Federal} de 1988 como resposta ao mandamento constitucional do direito à saúde como um "direito de todos" e um "dever do estado". O SUS baseia-se nos princípios da universalidade, integralidade, equidade, descentralização e

\footnotetext{
${ }^{11} \mathrm{O}$ consenso sobre a noção de que o "verdadeiro sexo" seria o biológico e a ideia de que tratamentos hormonais e cirúrgicos teriam mais sucesso que a psicanálise estava de acordo com o clima de modificações que envolvia a psiquiatria nos anos 1980. Jane Russo (2004) assinala o DMS III - O Manual Diagnóstico e Estatístico de Transtornos Mentais (Diagnostic and Statistical Manual of Mental Disorders - DSM), que é um manual para profissionais da área da saúde mental que lista diferentes categorias de transtornos mentais e critérios para diagnosticá-los, de acordo com a Associação Americana de Psiquiatria (American Psychiatric Association - APA). É usado ao redor do mundo por clínicos e pesquisadores bem como por companhias de seguro, indústria farmacêutica e parlamentos políticos - como o marco da virada biológica no campo da saúde mental. Segundo a autora, a partir deste momento a definição e classificação dos transtornos mentais torna-se central em oposição ao paradigma psicanalítico anterior. Essa biologização do humano "atingiu especialmente os transtornos/ desvios relacionados à sexualidade e ao gênero" (2004, p. 96).

${ }^{12}$ Agradeçemos ao Professor Guilherme de Almeida por sugerir tal discussão. Ver: ALMEIDA, Guilherme Silva de. (2012). "Repercussões Sociais da Assistência à Saúde do Transexual". In: SILVA, Eloísio Alexsandro da (Org.). Transexualidade: Princípios de Atenção Integral à Saúde. São Paulo: Livraria Santos Editora, p. 225-240.
} 
participação social. ${ }^{13}$

O Ministério da Saúde define o processo transexualizador como "um conjunto de estratégias assistenciais para transexuais que pretendem realizar modificações corporais de sexo, em função de um sentimento de desacordo entre seu sexo biológico e seu gênero" ${ }^{\prime 14}$

Esse procedimento foi regulamentado em 2008 através da Portaria número 457 do Conselho Federal de Medicina. Em 2013, o Ministério da Saúde ampliou a abrangência do processo transexualizador. ${ }^{15}$

Ainda assim, a demanda não é suprida pelos serviços de saúde públicos. Reclamações sobre o tempo de espera para poder participar do "Processo Transexualizador" no SUS são abundantes (BENTO, 2006; BORBA, 2014), inclusive entre as entrevistadas (O'DWYER, 2016), e por isso algumas pessoas trans acabam recorrendo a serviços privados ou à automedicação.

Por ser considerado um "procedimento irreversível", algumas condicionantes antecedem o processo: maioridade civil, acompanhamento psicoterápico por pelo menos dois anos e laudo psiquiátrico/psicológico favorável que ateste o diagnóstico de "transexualismo".

Para se ter acesso ao atendimento nesses serviços ${ }^{16}$, o sujeito precisa passar por uma avaliação psicológica que dura dois anos. Após esse período, o diagnóstico será confirmado ou negado.

\footnotetext{
${ }^{13}$ Ver PAIM, Jairnilson Silva. O que é o SUS. Rio de Janeiro, Editora Fiocruz, 2009. 144 p.

14 Disponível: www.brasil.gov.br/cidadania-e-justica/2013/03/cirurgias-de-mudanca-desex-sao-relaizadas-pelo-sus-desde-2008 . Acesso em 13 de outubro de 2015.

${ }^{15}$ A nova regulamentação aumentou o número de procedimentos ambulatoriais e hospitalares, incluiu procedimentos de redesignação sexual para homens trans - pessoas que se identificam como homens, mas que foram classificadas como mulheres no nascimento. Os procedimentos mais requisitados por homens trans em serviços de saúde são a hormonização e a retirada dos seios. Pessoas que se identificam como travestis também foram incorporadas. A idade mínima para o acompanhamento clínico e hormonoterapia foi reduzida de 21 para 18 anos. Por fim, cirurgias de plástica mamária com próteses de silicone e outras cirurgias corretivas foram acrescentadas ao processo.

${ }^{16}$ Apenas seis hospitais públicos no país são habilitados para a realização da redesignação sexual: o Hospital das Clínicas da Universidade Federal de Goiás, Goiânia (GO); o Hospital das Clínicas de Porto Alegre, da Universidade Federal do Rio Grande do Sul, Porto Alegre (RS); o Hospital Universitário Pedro Ernesto da Universidade Estadual do Rio de Janeiro (RJ); a Fundação da Faculdade de Medicina da Universidade de São Paulo (SP) e o Hospital das Clínicas da Universidade de Pernambuco em Recife (PE). Para realizar o Processo Transexualizador os hospitais precisam dispor de equipe multidisciplinar composta de médico-psiquiatra, cirurgião, psicólogo, endocrinologista e assistente social.
} 
“O Conselho Federal de Medicina considera transexual o portador de desvio psicológico permanente e identidade sexual, com rejeição do fenótipo e tendência à automutilação e autoextermínio, justificando sua inclusão na CID. A definição do transexualismo deve obedecer aos seguintes critérios mínimos: a) desconforto com o sexo anatômico natural; b) desejo expresso de eliminar os genitais, perder as características primárias e secundárias do próprio sexo e ganhar as do sexo oposto; c) permanência desses distúrbios de forma contínua e consistente por, no mínimo, dois anos; e d) ausência de outros transtornos mentais". (BARBOZA; SCHRAMM, 2012, p.20)

O Processo Transexualizador é estabelecido segundo três princípios; a autonomia, que prescreve que a pessoa "é competente para decidir sobre sua vida"; a igualdade de acesso à saúde, que deve ser universal, "sem preconceitos ou privilégios", e a beneficência, já que o objetivo do tratamento hormonal e cirurgia é "fazer o bem" ao indivíduo (BARBOZA; SCHRAMM, 2012).

Pode-se questionar se esses princípios realmente estão sendo respeitados. O diagnóstico pode ser negado, impossibilitando que a pessoa tenha autonomia para dispor do próprio corpo. Isto implica que o acesso ao serviço não é universal e nega a beneficência, já que resta ao sujeito permanecer em estado de sofrimento ou recorrer a maneiras não seguras de modificação corporal, por exemplo, a "bombação" ${ }^{17}$

Segundo o psiquiatra Saadeh e a psicóloga Monteiro Cordeiro (2012), o "transexualismo" é de difícil diagnóstico. Ainda assim, é imperativo que a equipe tenha certeza de que o candidato à cirurgia seja realmente transexual.

Para assegurar o acesso ao procedimento, o candidato precisa demonstrar que "a crença de ser membro do sexo oposto" está presente desde a infância, precisa rejeitar completamente os genitais e demonstrar desejo heterossexual, isto é, uma mulher transexual precisa se sentir atraída por homens e um homem transexual por mulheres.

\footnotetext{
${ }^{17}$ A "bombação" é uma prática que consiste na injeção de silicone industrial para criar seios, arredondar quadris, coxas e nádegas. É uma prática perigosa, porque o silicone aplicado é feito para veículos automobilísticos e pode "escorrer" dentro do corpo da pessoa, o que pode levar ao óbito.
} 
Para acompanhar o processo existe ainda o "teste de vida real", que é a capacidade de viver de acordo com "o gênero desejado". Segundo Bento (2006), isto é traduzido, na expectativa da equipe, na ideia de que mulheres transexuais ajam segundo padrões convencionais de feminilidade e homens trans apresentem comportamentos socialmente definidos como masculinos. Portanto, o "teste de vida real" traduz-se em uma exigência moral e não médica, que reconhece apenas um tipo de trajetória e narrativa de gênero (BENTO, 2006).

Márcia Arán (2012) entende que esse modelo pode ser modificado dentro do próprio SUS, já que a noção de saúde adotada pelo sistema não significa apenas ausência de doença, mas inclui também o não sofrimento psicológico. Logo, pessoas trans poderiam ter acesso aos serviços a partir dos princípios de não sofrimento e de autonomia, sem necessidade de diagnóstico, que, como apresentamos, pode causar exclusão. A saúde no SUS não é apenas ausência de doença, pessoas que não são consideradas doentes também têm direito aos serviços, já que é um direito universal ${ }^{18}$. As modificações corporais de pessoas trans poderiam acontecer a partir dessa lógica.

Almeida (2012) salienta que nem todas as pessoas que procuram o serviço desejam as mesmas intervenções. Entretanto, a concepção inerente ao "Processo Transexualizador" é de uma única trajetória possível de modificações corporais. Para algumas pessoas, a hormonização é suficiente, outras desejam somente a cirurgia. Esse tipo de escolha não é possível no modelo atual. Assim, um conjunto de pesquisadores - Almeida (2012), Arán (2012), Bento (2006) e Borba (2004) - estão de acordo com as críticas à proposta do Processo Transexualizador. Marcia Arán (2012) e Almeida (2012) entendem que o SUS pode suprir as demandas da população trans sem recorrer ao modelo da patologização. Para Almeida, a despatologização da transexualidade é uma questão de direitos humanos, pois, ao excluir os chamados "falsos transexuais", acaba por deixar tais indivíduos em situação de maior vulnerabilidade.

Amplamente discutido pelos estudos sobre transexualidade é o tópico

\footnotetext{
${ }^{18}$ Em um momento de ataque e desmonte aos serviços públicos e ao SUS no Brasil é importante ressaltar o direito de universalidade ao acesso e que esses procedimentos já acontecem dentro dos serviços. A crítica aqui feita não é de oposição, acreditamos no direito universal à saúde pública e também na importância de um atendimento humanizado e de acordo com as necessidades das pessoas trans.
} 
do nome social ${ }^{19}$ e do registro civil. Autores que se dedicam a questões jurídicas e éticas associadas à "mudança de sexo" assinalam que o direito brasileiro adota sem revisão ou crítica as definições médicas referentes à transexualidade. Por exemplo, a alteração do nome e sexo no registro civil só é possível após a cirurgia de transgenitalização que, por sua vez, requer o diagnóstico de "transexualismo". Os autores reiteram que tanto o direito quanto a medicina, nesses casos, anulam a autonomia dos sujeitos em prol de moralidades dominantes. A condicionalidade da alteração do registro civil mostra a soberania do determinismo biológico diante do direito à identidade e disposição do próprio corpo (VENTURA, 2010; VENTURA; SCHRAMM, 2009). A situação jurídica brasileira difere, por exemplo, da argentina. $\mathrm{O}$ direito argentino não estabelece a exigência cirúrgica para mudança do registro civil. ${ }^{20}$

Uma das entrevistadas [Duda] tentou ter acesso ao Processo Transexualizador no SUS. Ela descreve a experiência: " Foi complicado, eu fui, em abril de 2012, ao hospital, fizemos uma peregrinação e descobrimos que o centro de urologia é o que atende. Aí a mulher me falou que só teria vaga em novembro, eu respondi "até lá o que eu faço? Eu me mato? [risos]". ${ }^{21}$

Vitória teve experiência similar à de Duda. Por esses motivos ambas resolveram recorrer à automedicação e a médicos particulares. Ainda assim, a ida a médicos particulares não significa um atendimento melhor. Duda relata que procurou uma médica listada em seu plano de saúde que se recusou a atendê-la. Ela narra como a médica se recusou justificando que não atenderia "pessoas do seu tipo": "O plano de saúde que paga, ela não me atendeu e disse que não atenderia pessoas do meu tipo. Eu saí do consultório muito deprimida e dei um tempo, porque eu falei não sei mais o que fazer. Já estavam entrando em escassez as minhas possibilidades".

Já Vitória foi bem tratada pelo médico do plano de saúde, entretanto, ele não tinha conhecimentos suficientes para atendê-la, e a jovem acabou

\footnotetext{
${ }^{19} \mathrm{O}$ nome que está de acordo com a identidade de gênero da pessoa trans, escolhido pela própria, diferente do nome de registro.

${ }^{20} \mathrm{O}$ uso do nome social e a mudança do registro civil são reinvindicações do movimento trans e não existe lei que regulamente tal alteração dos documentos. Em geral, é preciso entrar com pedido judicial e aguardar a decisão de um juiz. Esses processos estão em ampla modificação, No Rio Grande do Sul, por exemplo, existe desde 2012 a "carteira do nome social", documento que equivale ao RG. http://www1.folha.uol.com.br/fsp/cotidiano/41250-travestis-do-rsvao-ganhar-rg-feminino.shtml. Acesso em 22 de outubro de 2016.

${ }^{21}$ Duda foi entrevistada presencialmente; tem 21 anos de idade.
} 
ensinando-lhe quais eram os melhores medicamentos. Pela falta de informação do profissional, Vitória volta-se cada vez mais para a Internet como fonte principal de informação e vai ao médico apenas como consultor.

Vitória pode ser classificada como uma "paciente expert" no sentido atribuído por Dumit (2012). O autor entende que as pessoas estão cada vez mais preocupadas com a saúde, que os fármacos estão mais presentes na vida diária e que há muitas informações de fácil acesso sobre essas substâncias. Os sujeitos não ficam passivos diante desse quadro. Portanto, uma maneira de lidar com os fármacos é justamente procurar saber o máximo possível sobre eles, fazer pesquisas, saber as próprias taxas e estar sempre vigilante - fazendo exames, lendo informações, indo ao médico com frequência. O "paciente expert" busca ativamente conhecimento sobre as substâncias que toma e sobre seu próprio corpo (DUMIT, 2012).

\section{A Patologização do Gênero}

Definir a transexualidade como um transtorno mental é legitimar o modelo binário de gênero no qual existe uma relação obrigatória entre gênero e sexo biológico. Neste quadro, o "natural" e o "normal" são as expressões culturais de gênero que estão em congruência com a fisicalidade da pessoa, independentemente do entendimento do gênero como socialmente construído. Portanto, a pessoa trans é considerada anormal, e a medicina aparece como mecanismo classificador e purificador dessa "anormalidade". A partir da ideia de que existem sintomas predefinidos para que alguém seja considerado um "transexual verdadeiro", a autonomia das pessoas é retirada, já que cabe ao saber médico - e não às próprias pessoas - decidir quem pode ter acesso às transformações corporais desejadas.

A definição médica patologizante da transexualidade utilizada no SUS vem sendo questionada por diversos autores (BENTO, 2006; ARÁN; MURTA 2009; VENTURA, 2010; LEITE JUNIOR, 2011; BORBA, 2014).

"A definição da transexualidade como 'transtorno' ou 'doença' baseia-se em uma determinada concepção de gênero" rígida e tradicional" (BENTO, 2006, p. 17). A partir de entrevistas com homens e mulheres transexuais, a antropóloga Berenice Bento demonstra que a teoria de Stoller, psiquiatra, fundamentada na relação da pessoa com a mãe, não é coerente com a realidade. As relações de seus entrevistados com as famílias eram diversas. Assim, partindo da experiência dos entrevistados, a autora questiona a definição do "transexualismo" enquanto patologia e entende que o corpo 
transexual demonstra a plasticidade do corpo humano.

Para Côrrea (1998), a transexualidade desafia a medicina enquanto disciplina "naquilo que talvez seja mais exclusivo ao discurso médico sobre o sexo e a sexualidade: sua definição anatômica da diferença sexual e sua concepção biologizante da determinação genética dos sexos" (p.70).

"O caso que melhor ilustra a fragilidade e a incongruência deste sistema de determinação do sexo pela medicina é o caso do transexual. Coerente genética, hormonal e anatomicamente, o transexual consegue fazer valer uma norma excepcional, que tem por base uma "convicção absoluta" e uma "vontade indiscutível" de pertencer ao sexo oposto àquele que seus genes, hormônios e órgãos sexuais normais atestam (termos utilizados em tratados médicos sobre o transexualismo)... o transexual talvez seja o único caso sobre o qual seria possível falar, hoje, em termos de perversão ou transgressão; não de uma norma medicamente estabelecida, mas da própria instância instauradora da norma: a medicina". (CÔRREA, 1998, p. 90)

Segundo Arán e Murta (2009), a população trans, no Brasil, vive em constante vulnerabilidade e encara a cirurgia como uma salvação, uma vez que esta permite a inclusão social. Entretanto, algumas pessoas desejam apenas a mudança na documentação e não a cirurgia, "o que nos faz pensar que a cirurgia não necessariamente seria indicada se vivêssemos num mundo onde a diversidade de gênero fosse possível" (ARÁN; MURTA, 2009, p. 19). Algumas pessoas já são reconhecidas da forma como querem e têm vida afetiva e sexual satisfatória, e só gostariam de modificar o registro civil. Outras podem considerar a cirurgia fundamental. Existem múltiplas possibilidades e "a individualização do cuidado é parte constitutiva de qualquer projeto baseado na integração da assistência" (ARÁN; MURTA, 2009, p.21).

Maria Eduarda, uma das entrevistadas, relata que, ao realizar pesquisas sobre o tema em sites de buscas na Internet, encontrou artigos sobre as teorias de Stoller e Benjamin. Duda narra um conforto inicial ao descobrir "o que eu tenho tem nome"; contudo, tal sensação é logo substituída pelo sofrimento por ter uma doença sem cura. A patologização do "transexualismo" causa danos individuais graves. "(... $)^{22}$ no meu caso foi

\footnotetext{
${ }^{22}$ Maria Eduarda é estudante de um curso de ciências humanas e por isso tem o vocabulário próximo ao da sociologia e antropologia.
} 
difícil entender as nomenclaturas e referências e foi difícil pelo estigma que todo instante estava sendo reforçado... mas o efeito psicológico é terrível porque você acaba acreditando."

A descoberta da categoria transexual enquanto doençaé simultaneamente central e paradoxal para as entrevistadas. Oferece conforto inicial dando sentido à experiência individual, mas esse possível sentido é rapidamente substituído pela noção violenta da "doença", que vem acompanhada da possibilidade de estigmatização.

O diagnóstico pode ser considerado uma forma de exclusão, porque estabelece uma única maneira de vivenciar a transexualidade ao definir "sintomas" que preveem, por exemplo, a heterossexualidade pós-transição, excluindo pessoas trans de outras orientações sexuais do diagnóstico e, logo, do acesso às mudanças corporais acompanhadas por médicos e serviços de saúde.

\section{Movimento Trans e Mudanças Recentes no Cenário Nacional e Internacional}

O movimento trans tem crescido consideravelmente nos últimos dez anos. A principal demanda é pelo fim da patalogização da transexualidade em prol de maior autonomia corporal e de modelos de gênero mais flexíveis. Outra pauta principal é a mudança de nome e sexo no registro civil sem a condicionalidade cirúrgica.

As críticas acadêmicas ao modelo médico atual de tratar a transexualidade estão em ressonância com a maior visibilidade do movimento trans e têm tido impacto de transformação. Recentemente, no DSM 5, o termo "Transtorno de Identidade de Gênero" foi substituído por "Disforia de Gênero". Os critérios para o diagnóstico são praticamente os mesmos, mas a mudança de nomenclatura indica respeito a diversidade de identidades de gênero por não "patologizar" a experiência. Além disso, a $\mathrm{APA}^{23}$ entende que o novo termo é mais descritivo que o anterior, sem que a falta de diagnóstico impeça o acesso aos serviços de saúde. Contudo, o pressuposto do problema mental permanece, já que a categoria permanece no Manual.

A par dessas mudanças, a transexualidade vem ganhando visibilidade midiática através de personalidades, e o movimento transexual ganha

${ }^{23}$ Associação Americana de Psiquiatria (American Psychiatric Association - APA). 
mais reconhecimento. Lima Carvalho (2011) assinala que o movimento transexual no Brasil - diferentemente das outras causas LGB - só conseguiu inserir a transexualidade no debate público nos anos 1990 com a ampla popularidade de Roberta Close.

Até o final dos anos 1990, a palavra transexual não era utilizada no país. Existiam organizações de travestis, como a Associação das Travestis e Liberados (ASTRAL), fundada em 1992. Esses grupos de travestis formavam-se através de dois modelos; a partir da luta contra violência policial em relação à prostituição e através de ONGs que lutavam contra a epidemia de HIV/AIDS. Essas organizações de travestis compartilhavam espaços do movimento de gays e lésbicas; em 1995 funda-se a Associação Brasileira de Gays, Lésbicas e Travestis (ABGLT). Nos anos 2000, o T passa a referir-se também a transexuais por influência do movimento LGBT internacional ${ }^{24}$.

Enquanto os grupos de travestis surgem nos anos 1990 em função da violência e AIDS, os grupos de transexuais surgem nos anos 2000 reivindicando procedimentos médicos, mudanças na legislação sobre registro civil e a despatologização.

A luta pela despatologização cresce no Brasil nos últimos anos e tem se desdobrado em ações como a campanha "Sou trans e mereço respeito". A luta pela aprovação da Lei João $\mathrm{Nery}^{25}$ - projeto de lei que tem como pretensão permitir que pessoas transexuais tenham seu gênero e nome modificado nos registros civis sem precisar da cirurgia de transgenitalização - também contribuiu para maior publicização da questão transexual. Tal lei pretende garantir o direito à identidade de gênero segundo declaração, bastante próxima à lei argentina de 2012.

No cenário internacional, outros eventos têm promovido maior visibilidade midiática da transexualidade. São destaque Laverne Cox, primeira mulher transexual a receber um Emmy de melhor atriz pelo seu papel na série "Orange is the new black", e Caitlyn Jenner. Caitlyn, antes conhecida como Bruce Jenner, ganhou a medalha de ouro pelos EUA nos Jogos Olímpicos de 1976 tornando-se um herói no país por ter vencido a

\footnotetext{
${ }^{24}$ Inicialmente, a palavra transgênero foi rejeitada no Brasil, por ser um estrangeirismo e pela confusão com a palavra "transgênico", assunto em voga à época. O termo "transexual" foi incorporado aos poucos.

${ }^{25}$ João Nery é um homem transexual notório no Brasil por ter escrito suas memórias no livro “Viagem Solitária” de 2011.
} 
União Soviética em pleno período de Guerra Fria. Nos anos 2000 participa de um reality show chamado "Keeping up with the Kardashians", que versa sobre as irmãs Kardashians. Jenner participa do reality como padrasto das protagonistas. No início de 2015, Jenner revela para o mundo ser uma mulher transexual. Desde então, ela tem atuado como porta-voz do movimento transexual. A história de Jenner é similar à de Jorgensen, narrada por Meyerowitz (2014). Ambas estavam em posições sociais entendidas como extremamente masculinas - Jenner como atleta e Jorgensen no exército - e fazem a transição de forma pública, dando entrevistas nos principais meios de comunicação.

Ainda no meio internacional e jornalístico, o jornal The New York Times lançou uma série de artigos sobre transexualidade ao longo do ano de 2015.

No Brasil, é importante destacar o episódio do programa Globo Repórter sobre transexualidade em novembro de 2014 e a notabilidade de Thammy Gretchen, filho da cantora Gretchen, que em 2015 assumiu-se como homem transexual e também tratou de sua transição de forma pública, participando, inclusive, do programa de entrevistas na TV do Programa do Jô, em julho de 2015.

A recente visibilidade é importante para as entrevistadas, porque elas se posicionam como parte do movimento social e lutam especialmente pelo reconhecimento do nome social, entendendo-se que nenhuma delas pode ter o registro civil modificado. Também demandam acesso a serviços de saúde sem a precedência do diagnóstico e por isso lutam pela despatologização da transexualidade ${ }^{26}$.

\section{Conclusão}

A dificuldade no acesso a serviços de saúde públicos e privados leva as pessoas trans a recorrem à automedicação. Os mecanismos de busca na Internet e grupos de pessoas transexuais nas redes sociais virtuais são imprescindíveis como fontes de informação graças à exclusão sofrida.

Apesar da recente mudança na classificação do "transexualismo" no DSM 5, a transexualidade continua sendo entendida pelo saber médico e

\footnotetext{
26 Tais mudanças no ambiente público não tiveram efeitos práticos nem no Processo Transexualizador nem nos consultórios particulares, segundo o relato das entrevistadas, o que nos leva a considerar limites da difusão do debate sobre transexualidade.
} 
pelo senso comum como uma anomalia, doença ou transtorno, evidenciando as normas de gênero imbrincadas nas noções de normalidade e doença e o papel da medicina como a ciência que tem o poder de normatização.

A categorização da transexualidade como doença é ambígua: ao mesmo tempo que garante o acesso a serviços de saúde públicos - ainda que esse acesso seja dificílimo na prática - restringe a entrada no processo pela necessidade do diagnóstico. Almeida (2012) e Bento (2006) reiteram a exclusão causada pela necessidade do diagnóstico e entendem que os procedimentos médicos como tratamento hormonal e cirurgia poderiam ser oferecidos no âmbito do SUS independentemente dessa condicionante.

A discussão sobre a questão transexual cresce em importância nacional e internacional. Em 28 de abril de 2016, a presidente Dilma Rousseff aprova decreto ${ }^{27}$ que autoriza a população trans a utilizar o "nome social" nos órgãos do serviço público federal. O "nome social" é a forma como chamada, o nome que a pessoa trans escolhe e que está de acordo com sua identidade de gênero, diferentemente do seu nome no registro civil. Esse decreto abre precedentes, por exemplo, para a utilização do "nome social" no Processo Transexualizador no SUS e em universidades federais ${ }^{28} 29$.

27 Disponível em: http://www.planalto.gov.br/ccivil_03/_Ato2015-2018/2016/Decreto/ D8727.htm. Acesso em 24 de agosto de 2016.

28 Outra mudança importante ocorreu em agosto de 2014, quando a Comissão Especial de Diversidade Sexual do Conselho Federal da OAB publicou nota técnica intitulada: "SOBRE A APLICABILIDADE DA LEI MARIA DA PENHA À VIOLÊNCIA DOMÉSTICA CONTRA TRANSEXUAIS E TRAVESTIS". Na nota consta: "A Lei, ao selecionar a mulher como elemento vulnerável, por certo não o fez em razão de presunção de que a mulher - como sexo - é biologicamente mais fraca que o homem e, portanto, deveria ser protegida." Diz ainda que "É a mulher como gênero feminino, portanto, o objeto de proteção da lei, em razão do estereotipado papel social e cultural que exerce na sociedade [...] É a violência motivada em razão deste estereótipo de inferioridade que autoriza a relativização da igualdade formal para, através da ação afirmativa do Estado, proteger a pessoa de gênero feminino contra quem quer que seja o autor de tal violência. Justamente pela violência ser perpetrada em razão do gênero, e não do sexo, que se admite que o sujeito ativo seja tanto homem quanto mulher". Por fim, "A Lei Maria da Penha não cria qualquer restrição às transexuais e travestis, tampouco exige prévia retificação do registro civil ou cirurgia de adequação de sexo, e onde a lei não restringe, não cabe ao intérprete fazê-lo. Estabelecida proteção da mulher como gênero, e não como sexo, mostra-se plenamente aplicável à violência doméstica praticada contra transexuais e travestis do gênero feminino". Portanto, esta nota entende que a lei Maria da Penha pode ser aplicada para mulheres transexuais e travestis e também em casais homoafetivos.

${ }^{29}$ Enquanto o artigo passava pelo processo final de revisão, em março de 2018, o STF decidiu permitir que pessoas transexuais e transgêneros possam alterar o registro civil sem a necessidade de realização de cirurgia ou laudo diagnóstico. Ainda que a medida não tenha caráter de lei apresenta uma vitória do movimento trans por direitos e inclusão social. 
"A garota dinamarquesa", filme de 2015 dirigido por Tom Hopper e inspirado no livro de mesmo título de David Ebershoff (2000), é lançado. Estreia Eddie Redmayne como Elbe, uma das primeiras mulheres trans a fazer cirurgia de redesignação sexual. Gerda (Alicia Vikander) e Einer Wagner são um casal de artistas que vive em Copenhagen nos anos de 1920. Gerda pede que seu marido, Einer, pose vestido de mulher quando a modelo que seria pintada falta ao compromisso. Esse momento revela para Einer uma identificação feminina. A partir deste momento, surge Lili Elbe, e a identidade masculina de Einer vai sendo progressivamente substituída. A existência entre as duas identidades, Lili e Einer, começa a ter um peso psicológico para Lili, que procura a ajuda de diversos psicólogos. Até que Lili conhece um médico que relata ter conhecido pessoas como ela e sugere uma cirurgia de redesignação sexual. No filme, Lili seria a primeira pessoa a passar por tal procedimento, mesmo assim, ela aceita os perigos e riscos de uma cirurgia nunca antes feita devido ao seu desejo intenso de modificação corporal, mas acaba falecendo de complicações cirúrgicas.

O filme foi bem recebido pela crítica cinematográfica, Vikander ganhou o prêmio de melhor atriz coadjuvante no Oscar por seu papel como Gerda, e Redmayne foi nominado para o Oscar de melhor ator pelo papel de Lili. Entretanto, o fato de um ator homem cisgênero ${ }^{30}$ interpretar uma mulher transexual causou reação negativa da militância transexual ${ }^{31}$. $\mathrm{O}$ argumento principal é que esse tipo de papel deveria ser interpretado por mulheres transexuais, porque elas teriam um conhecimento profundo da experiência e também para dar oportunidades para pessoas trans na indústria cinematográfica, já que elas são sistematicamente excluídas do mercado de trabalho.

Os debates públicos sobre a questão trans, o crescente movimento social e as críticas acadêmicas sobre a patologização da transexualidade podem indicar um processo de maior aceitação de identidades de gênero que operam fora do modelo binário que associa sexo genital e gênero. Portanto, podemos antecipar mudanças nas leis sobre registro civil e no Processo

\footnotetext{
${ }^{30} \mathrm{O}$ termo é utilizado para se referir a pessoas cuja identidade de gênero é a mesma que a designada no nascimento, em oposição a pessoas transgênero. Inicialmente utilizado no movimento LGBTQI, a palavra vem se disseminando e passa também a ser utilizada em artigos acadêmicos.

31 Para saber mais: http://www.independent.co.uk/arts-entertainment/films/news/thereal-reason-eddie-redmayne-was-cast-as-a-trans-woman-in-the-danish-girl-10480658.html. Acesso em 24 de agosto de 2016.
} 
Transexualizador no SUS. Por exemplo, a aprovação da lei João Nery poderia partir do decreto que permite o uso do nome social nos órgãos e serviços federais, assim a modificação dos registros civis poderia acontecer sem necessidade de diagnóstico ou intervenção médica, como é o caso da Argentina. A demanda dos movimentos sociais também pode levar à ampliação das vagas no Processo e a uma flexibilização quanto à necessidade do diagnóstico tanto para a mudança do nome quanto para o acesso a serviços médicos de acompanhamento a modificações corporais. Tendo em vista as mobilizações recentes do movimento trans e a publicização positiva de histórias de pessoas trans através de figuras públicas, do cinema e da mídia - como no caso do personagem trans Ivan, na novela "A força do querer" da Rede Globo - é possível antever uma maior aceitação social e diminuição do estigma em relação à transexualidade.

\section{Referências}

ALMEIDA, Guilherme Silva de.

(2012). Repercussões Sociais da Assistência à Saúde do Transexual. In: Eloísio Alexsandro da Silva (Org.); Transexualidade: Princípios de Atenção Integral à Saúde. São Paulo, Livraria Santos Editora.

ARÁN, Márcia.

(2012). Do Diagnóstico de Transtorno de Identidade de Gênero às Redescrições da Experiência da Transexualidade: 0s Desafios do Atendimento Psicológico na Rede Pública de Saúde. In: Eloísio Alexsandro da Silva (Org.); Transexualidade: Princípios de Atenção Integral à Saúde. São Paulo, Livraria Santos Editora.

ARÁN, Márcia; MURTA, Daniela

(2009). Do diagnóstico ao transtorno: de identidade de gênero às redescrições da experiência da transexualidade: uma reflexão sobre gênero, tecnologia e saúde. Physis: Revista de Saúde Coletiva, Rio de Janeiro, v. 19, n. 1, p.15-41.

BARBOZA, Heloísa Helena; SCHRAMM, Fermin Roland.

(2012). Princípios Bioéticos Aplicados à Transexualidade e sua Atenção à Saúde.
In: Eloísio Alexsandro da Silva (Org.). Transexualidade: Princípios de Atenção Integral à Saúde. São Paulo, Livraria Santos Editora.

BENEDETTI, M. R.

(2005). Toda feita. 0 corpo e o gênero das travestis. Rio de Janeiro, Garamond.

BENJAMIN, Harry.

(1966). The Transsexual Phenomenon. New York, Julian Press.

BENTO, Berenice.

(2006). A reinvenção do corpo: sexualidade e gênero na experiência transexual. Rio de Janeiro, Garamond. 256 p.

BORBA, Rodrigo.

(2014). Sobre os obstáculos discursivos para a atenção integral e humanizada à saúde de pessoas transexuais. Sexualidad, Salud y Sociedad, v. 17, p. 66-97.

CANGUILHEM, Georges.

(1990). 0 normal e o patológico. Rio de Janeiro, Forense Universitaria. 
CONRAD, Peter.

(2007). The medicalization of society: on the transformation of human conditions into treatable disorders. Baltimore, Jhu Press.

CORRÊA, Marilena Villela.

(1998). Sexo, Sexualidade e Diferença Sexual no Discurso Médico: algumas reflexões. In: Maria Andréa Loyola (Org.); A sexualidade nas Ciências Humanas. Rio de Janeiro, Ed Uerj.

CORRÊA, Mariza.

(2004). Não se nasce homem. Trabalho apresentado no encontro "Masculinidades/ Feminilidades", nos Encontros Arrábida, Lisboa.

DUARTE, Luiz Fernando Dias.

(1986). Da Vida Nervosa: nas classes trabalhadoras urbanas. Rio de Janeiro, Jorge Zahar.

DUARTE, Luiz Fernando Dias.

(2012). Pessoa e indivíduo. In: Antonio Carlos de Souza Lima; Antropologia e Direito: temas antropológicos para estudos jurídicos. Rio de Janeiro, Laced.

DUMIT, Joseph.

(2012). Drugs for life: How Pharmaceutical Companies Define Our Health. Durham, Duke University Press.

EBERSHOFF, David.

(2000). The Danish girl. Viking Press.

EVANS-PRITCHARD, E. E.

(1978). Os Nuer. São Paulo, Perspectiva.

GOFFMAN, Erwin.

(1982). On face-work. In: Erving Goffman; Interaction ritual; essays in face-to-face behavior. Chicago, Aldine Pub. Co.

HEILBORN, Maria Luiza.

(2006). Entre as tramas da sexualidade brasileira. Estudos Feministas, Florianópolis, v. 1, n. 14.

HENRI-CASTELL. Pierre.

(2001). Algumas reflexões para estabelecer a cronologia do "fenômeno transexual" (1910-
1995). Revista Brasileira de História, São Paulo, V. 21, n. 41, p.77-1-1

ILLOUZ, Eva.

(2011). 0 amor nos tempos do capitalismo. Rio de Janeiro, Zahar.

LEITE JUNIOR, Jorge.

(2011). Nossos corpos também mudam: a invenção das categorias "travesti" e "transexual" no discurso científico. São Paulo, Annablume.

LIMA CARAVALH0, Mario Felipe.

(2011). de. De "doidas e putas" a "respeitáveis militantes": um histórico do movimento de travestis e transexuais no Brasil". 35a Encontro Anual da ANPOCS GT 32 - Sexualidade e Gênero: sociabilidade, erotismo e política.

MACHADO, Paula Sandrine.

(2005). Quimeras da ciência: a perspectiva de profissionais de saúde em caso de intersexo. Revista Brasileira de Ciências Sociais, São Paulo, v. 20, n. 59, p.67-80.

MEYEROWITZ, Joanne.

(2004). How Sex Changed: a history of transsexuality in the United States. United States of America, Harvard University Press.

NERY, João.

(2011). Viagem solitária. Leya Brasil.

O'DWYER, Brena.

(2016). A construção do gênero nas relações amorosas: um estudo com mulheres transexuais jovens e sobre o processo de feminização. Dissertação de mestrado apresentada ao Programa de Pós-graduação em Saúde Coletiva (PPGSC) da Universidade do Estado do Rio de Janeiro (UERJ).

PAIM, Jairnilson Silva.

(2009). 0 que é o SUS. Rio de Janeiro, Editora Fiocruz.

PAIS, J.M.

(1993). Culturas juvenis. Lisboa, Imprensa Nacional Casa da Moeda. 
RUSSO, Jane.

(2004). Do desvio ao transtorno: a medicalização da sexualidade na nosografia psiquiátrica contemporânea. In: Adriana Piscitelli; Maria Filomena Gregori; Sérgio Carrara (Orgs.); Sexualidade e saberes: convenções e fronteiras. Rio de Janeiro, Garamond.

SAADEH, Alexandre; CORDEIRO, Desiree Monteiro.

(2012). "Abordagem Diagnóstico e Acompanhamento Pré-operatório do Portador de Transtorno de Identidade de Gênero". Eloísio Alexsandro da Silva (Org.); Transexualidade: Princípios de Atenção Integral à Saúde. São Paulo, Livraria Santos Editora.

SALEM, Tania.

(2007). 0 casal grávido: disposições e dilemas da parceria igualitária. Rio de Janeiro, Editora FGV.

STOLLER, Robert J.

(1982). A Experiência Transexual. Rio de Janeiro, Imago.

VENTURA, Miriam; SCHARAMM, Fermin ROLAND. (2009). Limites e possibilidades: do exercício da autonomia nas práticas terapêuticas de modificação corporal e alteração da identidade sexual. Physis: Revista de Saúde Coletiva, Rio de Janeiro, v. 19, n.1.
VENTURA, Mirian.

(2010). A transexualidade no tribunal: saúde e cidadania. Rio de Janeiro, Ed Uerj.

ZAMBRANO, Elizabeth; HEILBORN, Maria Luiza. (2012). Identidade de gênero. In: Antonio Carlos de Souza Lima (Org.); Antropologia e Direito: Temas antropológicos para estudos jurídicos. Rio de Janeiro, Laced.

\section{ZILLI, Bruno.}

(2017). Teorias que libertam: narrativas de intelectuais brasileiros sobre engajamento em Direitos Sexuais. Interseções, v. 19, n. 1.

ZORZANELLI, Roberta T.; ORTEGA, Francisco; BEZERRA, Jr, Benilton.

(2014). Um panorama sobre as variações em torno do conceito de medicalização entre 1950-2010. Ciência e Saúde Coletiva, v. 19.

\section{Recebido em}

fevereiro de 2017

Aprovado em

janeiro de 2018 